\title{
Strategic Position and Tuning of UPFC using Multiple Indices and Flower pollination Algorithm for Contingency Management
}

\author{
Sravana Kumar Bali, B.Durgaprasad, A.Jagadeesh, V.Raj Kumar
}

\begin{abstract}
In this paper, a technique was proposed in the presence of UPFC to optimize the sizing of generators with Flower Pollination algorithm. The UPFC is based on an index incorporating both the L-index and the LUF index. For tuning the generators, a multi objective function has been selected. The multi-objective feature consists of deviation of voltage, cost of active generation of power and loss of transmission line. This approach was tested and implemented for regular loading and extreme network conditions due to line failure (contingency situation) on an IEEE 30 test bus system.
\end{abstract}

Keywords:Optimal Reallocation; UPFC; Flower Pollination Algorithm; Voltage Stability

\section{INTRODUCTION}

Optimalpower flow or optimal generator reallocation consists of optimizing an objective function when operational constraints are present. To solve the OPF problem, a lot of methods have been developed so far. In [1] Zhang et al. suggested a revised method for solving OPF based on multi-objective evolutionary algorithms. For obtain a uniformly distributed pareto-optimal solution, an adapted Tchebycheff decomposition approach was used. A solution to the power system's optimum energy flow problem was obtained using various methods such as Colliding Bodies Optimization algorithm [2], PSO optimization with aging manager and challenger [3], adaptive group search optimization [4].

FACTS components have very important role in further enhancing the impact of the power systems solution on the OPF problem. Mahdad and Srairi [5] used the adaptive flower pollination algorithm combined with SVC to resolve the OPF in the case of failures in the generating units. UPFC is a better FACTS tool that has been used to mitigate transmission losses and network operating costs [6-7], power system loadability, congestion management and various other applications. For the optimum power flow with UPFC, the Flower Pollination Algorithm was used in this article. UPFC has been put in the process using LUF and L-index. For a poly-objective feature, specifically decreasing deviation of voltage Cost of active power generation and loss of transmission line, the optimal tuning of generators was achieved. True and imaginary generation of power results and bus voltage restrictions are taken as optimization

Revised Manuscript Received on December 13, 2019.

\# Correspondence Author

Sravana Kumar Bali", EEE department, GITAM deemed to be University, Visakhapatnam, INDIA. Email: sravanbali@gmail.com

B.Durgaprasad*,A.Jagadeesh**,V.Raj Kumar ${ }^{* * *}$ EEE department GITAM deemed to be University, Visakhapatnam, INDIA. Email: durga206@gmail.com,Email: jagadeesh.adari@gmail.com requirements. To prove the validity of the novel procedure, the results of optimum tuning without and with UPFC were compared.

\section{II.INDEX FOR PLACEMENT OF UPFC}

A. L-index: The expression for $\mathrm{L}$ - index is given in Equation (1). $\mathrm{F}_{\mathrm{pq}}$ indicates complex parameters, $\mathrm{V}_{\mathrm{q}}$ indicates magnitude of voltage at bus $q$ and $V_{j}$ indicates magnitude of voltage at bus $p$.

$$
\text { Lindex }=\left|1-\sum_{q=1}^{g} F_{p q} \frac{V_{q}}{V_{p}}\right|
$$

B. Line Utilization Factor (LUF): LUF is an index indicated for formative the congestion of the transmission lines as given in equation 4 .

$$
L U F=\frac{M V A_{p q}}{M V A_{p q}{ }^{\max }}
$$

presented by Equation (3)

\section{Objective function is}

$$
\mathrm{Min} \mathrm{O}=\mathrm{Min}\left(\mathrm{W}_{1} * \mathrm{O}_{1}+\mathrm{W}_{2} * \mathrm{O}_{2}+\mathrm{W}_{3} * \mathrm{O}_{3}\right)
$$

Where, $\mathrm{O}_{1}$ is the Fuel cost given by

$$
\mathrm{O}_{1}=\min \left(\sum_{i=1}^{n g}\left[a_{i}+b_{i} P_{G i}+c_{i} P_{\mathrm{Gi}}^{2}\right]\right)
$$

$\mathrm{O}_{2}$ is the Real power loss

(5)

$\mathrm{O}_{3}$ is the deviation of voltage

$$
\begin{gathered}
\mathrm{O}_{3}=\min (V D)=\min \left(\sum_{k=1}^{N b u s}\left|V_{k}-V_{\mathrm{k}}^{\mathrm{ref}}\right|^{2}\right) \\
\mathrm{O}_{2}=\min \left(\sum_{i=1}^{n t l} \operatorname{real}\left(S_{\mathrm{pk}}^{\mathrm{q}}+S_{\mathrm{kp}}^{\mathrm{q}}\right)\right)
\end{gathered}
$$

\section{Flower Pollination Algorithm}

Algorithm represented in the form flow chart as shown below 
Strategic Position and Tuning of UPFC using Multiple Indices and Flower pollination Algorithm for Contingency Management

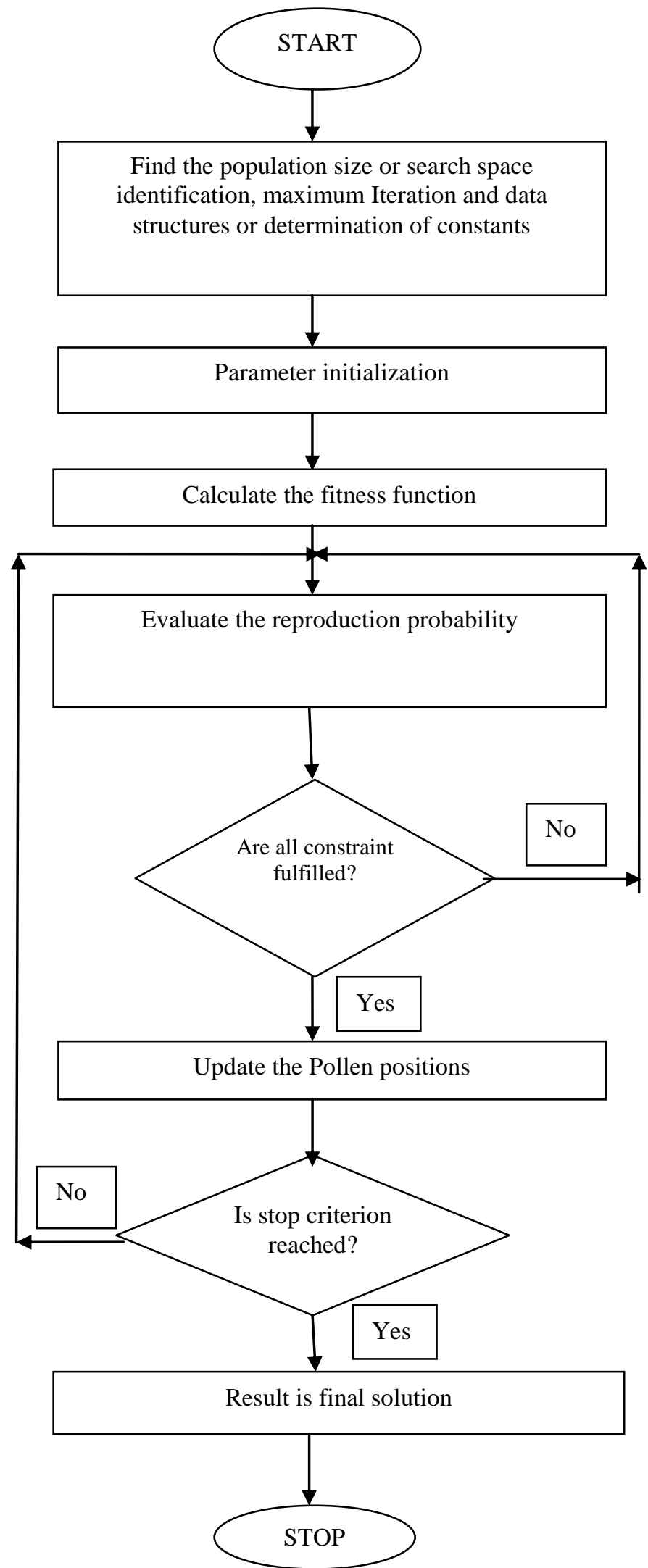

Fig.1 Flower Pollination Algorithm Flowchart

\section{PROPOSED METHODOLOGY}

The process for the projected technique mentioned in Fig. 2

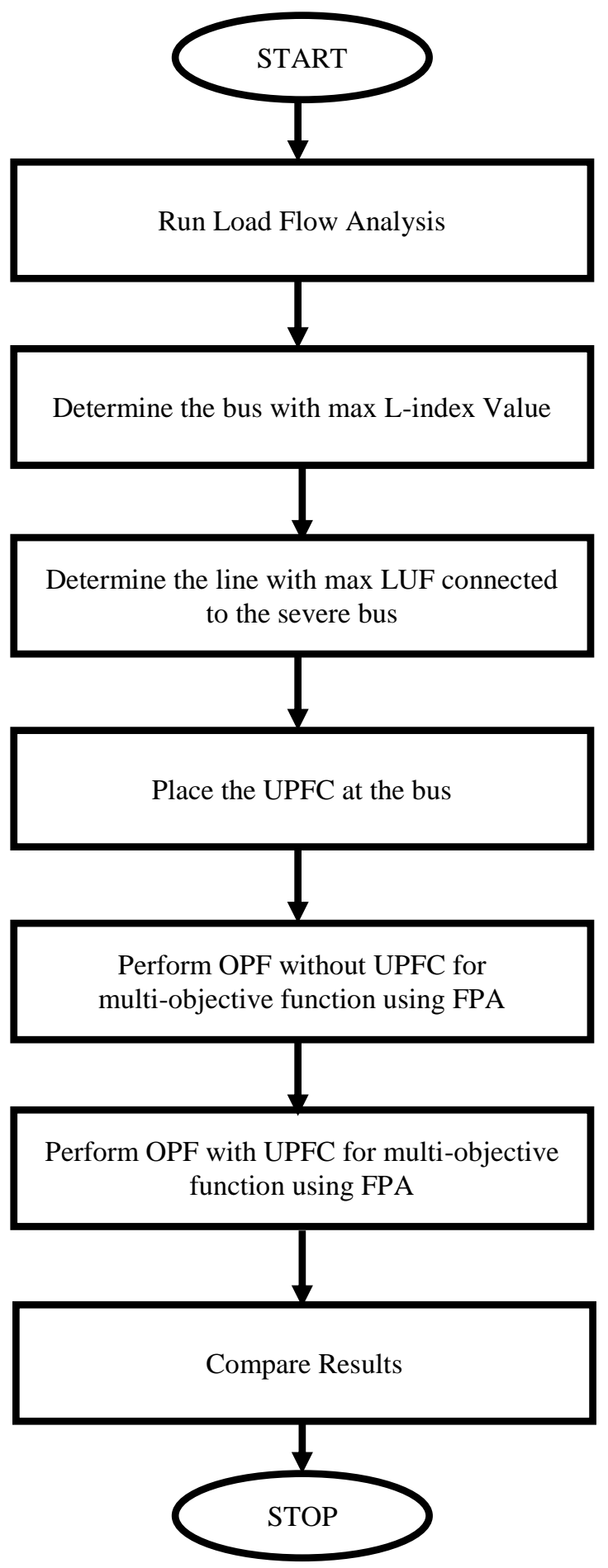

Fig.2 Flow Chart for the illustration of the proposed methodology

\section{RESULTS AND DISCUSSION}

Contingency study for the IEEE 30 bus scheme is done and it is seen that outage of 27-28 results in more damage to the network, reflected in L-index value of 0.4522 p.u $(\max )$ as presented in Table 1. It is seen from Fig. 3 that line $27-30$ is the severe-most line for line $27-28$ contingency. 
Therefore, Single linecontingency for 27-28 and UPFC at bus 30 and line 27-30 has been considered for the study.

Table-I: Feeble Bus in IEEE 30 Structure

\begin{tabular}{|c|c|c|c|}
\hline RANK & Bus No & Line Outage & L-Index \\
\hline 1 & 30 & $27-28$ & 0.4522 \\
\hline 2 & 19 & $9-10$ & 0.1918 \\
\hline 3 & 30 & $27-30$ & 0.1793 \\
\hline 4 & 29 & $27-29$ & 0.1613 \\
\hline 5 & 14 & $4-12$ & 0.1591 \\
\hline 6 & 21 & $10-21$ & 0.1416 \\
\hline 7 & 26 & $25-27$ & 0.1375 \\
\hline 8 & 20 & $10-20$ & 0.1341 \\
\hline 9 & 30 & $6-28$ & 0.1298 \\
\hline 10 & 19 & $19-20$ & 0.117 \\
\hline 11 & 17 & $10-17$ & 0.1167 \\
\hline 12 & 30 & $29-30$ & 0.1163 \\
\hline 13 & 30 & $3-4$ & 0.1151 \\
\hline 14 & 30 & $4-6$ & 0.1041 \\
\hline 15 & 26 & $10-22$ & 0.102 \\
\hline 16 & 26 & $22-24$ & 0.102 \\
\hline 17 & 30 & $6-10$ & 0.0938 \\
\hline 18 & 30 & $12-15$ & 0.0938 \\
\hline 19 & 30 & $23-24$ & 0.0934 \\
\hline 20 & 30 & $21-23$ & 0.0921 \\
\hline 21 & 30 & $12-14$ & 0.0907 \\
\hline 22 & 30 & $12-16$ & 0.0904 \\
\hline 23 & 30 & $15-18$ & 0.0902 \\
\hline 24 & 30 & $14-15$ & 0.0898 \\
\hline 25 & 30 & $18-19$ & 0.0898 \\
\hline 26 & 30 & $15-23$ & 0.0898 \\
\hline 27 & 30 & $16-17$ & 0.0894 \\
\hline 28 & 30 & $6-7$ & 0.0867 \\
\hline 29 & 30 & $6-9$ & 0.0857 \\
\hline 30 & 30 & $24-25$ & 0.0823 \\
\hline
\end{tabular}

\section{LUF Index (p.u.)}

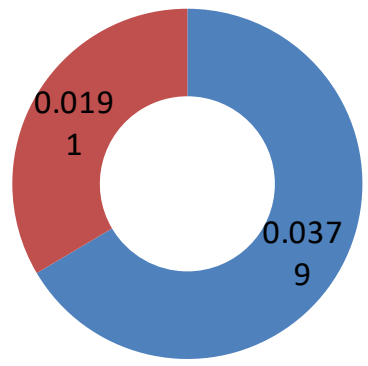

Line No.27-30 $\quad$ Line No.29-30

Fig.3 Severe Line at 27-28 contingency condition is 27-30

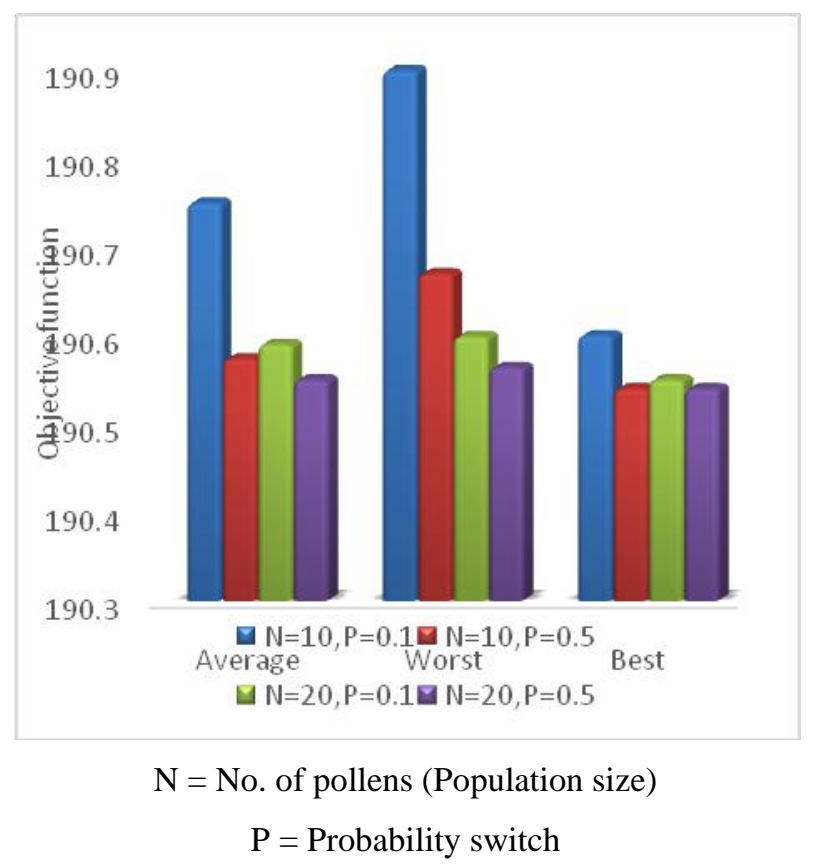

Fig.4Analysis of Objective Function value by varying Flower Algorithm Parameters

A number of values of $\mathrm{N}$ and $\mathrm{P}$ have been checked and the results are presented in Fig. 4. It is noted that for $\mathrm{N}=20, \mathrm{P}=$ 0.5 indicates the least average and best result of the objective function.

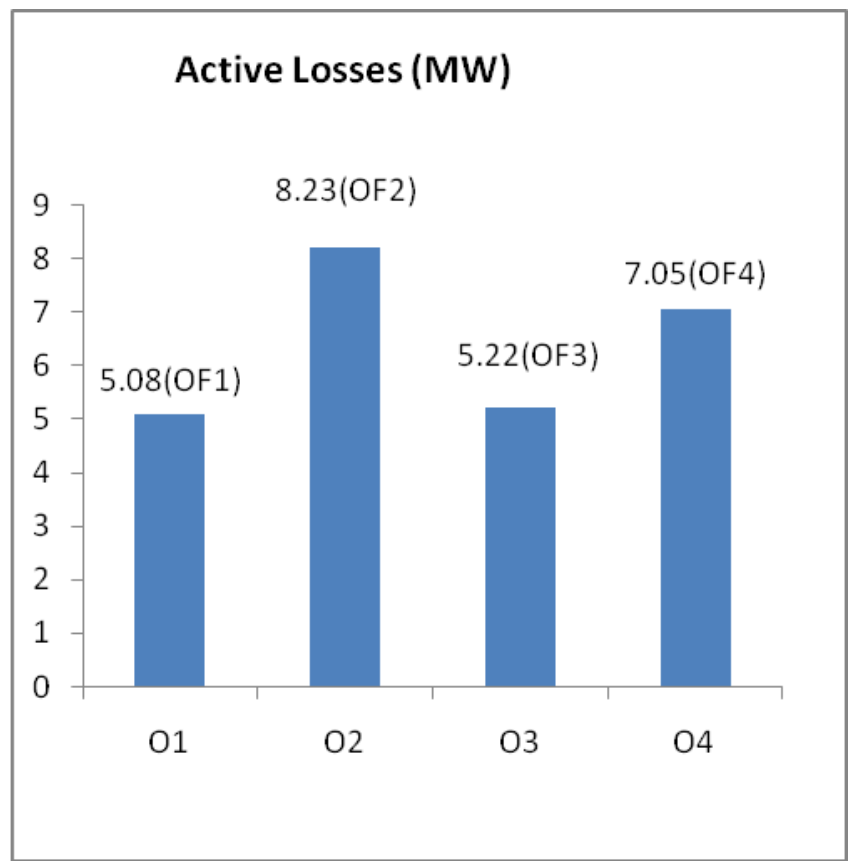

Fig.5 Real power loss vs. objective function 
Strategic Position and Tuning of UPFC using Multiple Indices and Flower pollination Algorithm for Contingency Management

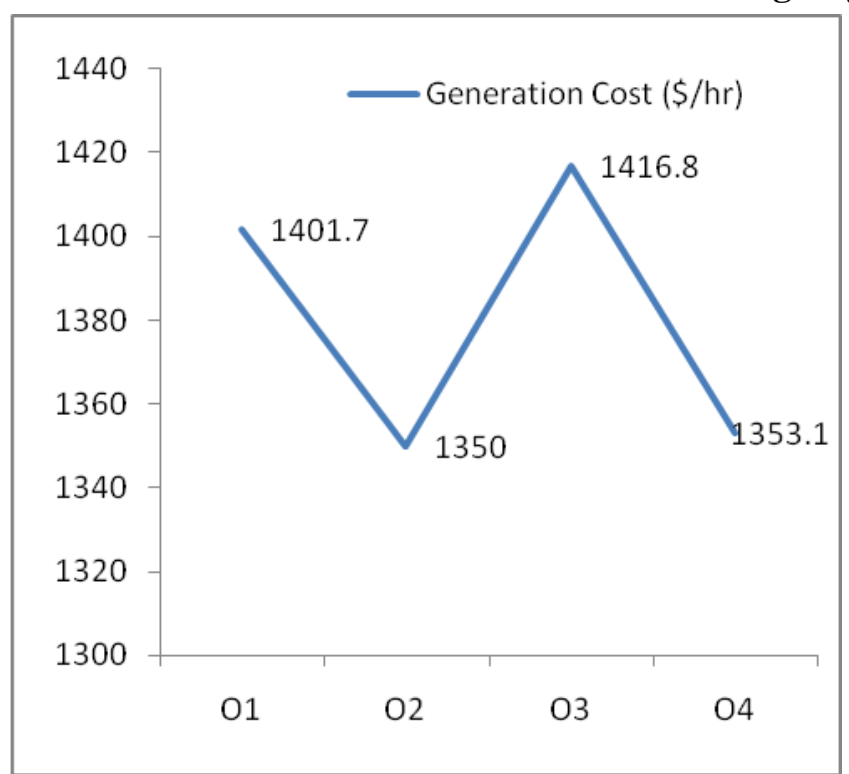

Fig. 6 Generation cost vs. objective function

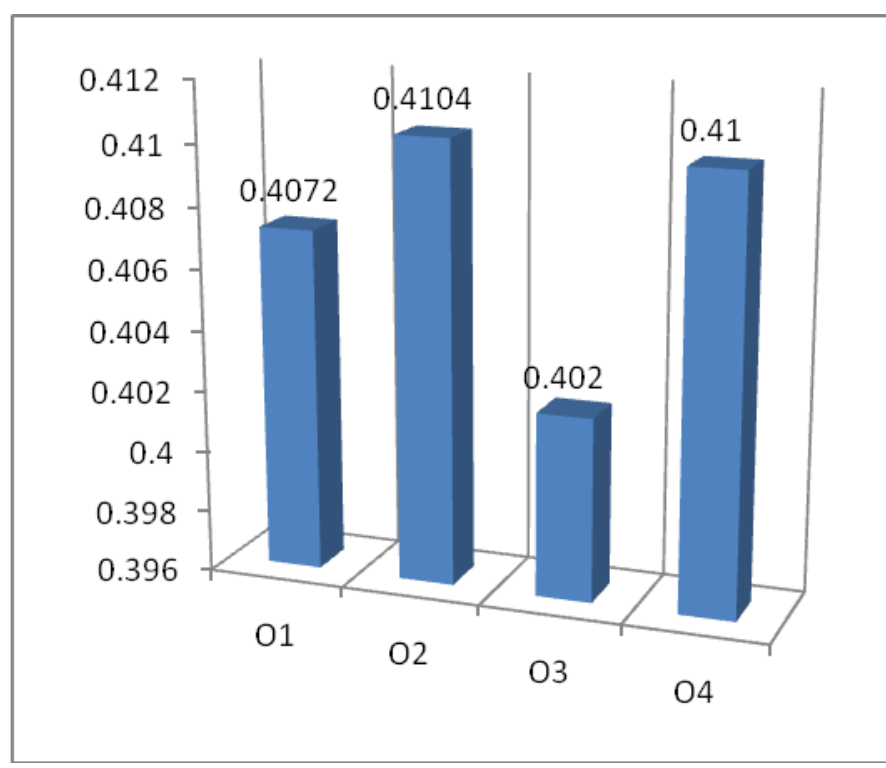

Fig.7 Voltage deviation vs. objective function

O1 - merelyTransmission losses

O2- merely cost of Generation

O3- merelydivergence of voltage

O4 - multi objective function

The network elements for single objective and multi-objective function are shown in Figures 5, 6, and 7. Multi objective function is seen to be apt for network elements.

Table-II:ASSESSMENT OF NETWORK ELEMENTS FOR WITHOUT CONTINGENCY \& CONTINGENCYWITH UPFC PLACED AT 27-30

\begin{tabular}{|c|c|c|c|}
\hline \multirow{3}{*}{$\begin{array}{l}\text { Loading } \\
\text { Condition }\end{array}$} & \multirow{3}{*}{ Parameter } & \multicolumn{2}{|c|}{ FPA } \\
\hline & & FPA-OPF & FPA-OPF \\
\hline & & UPFC & UPFC \\
\hline & PG1 & 115.517 & 87.0542 \\
\hline & PG2 & 50 & 50 \\
\hline
\end{tabular}

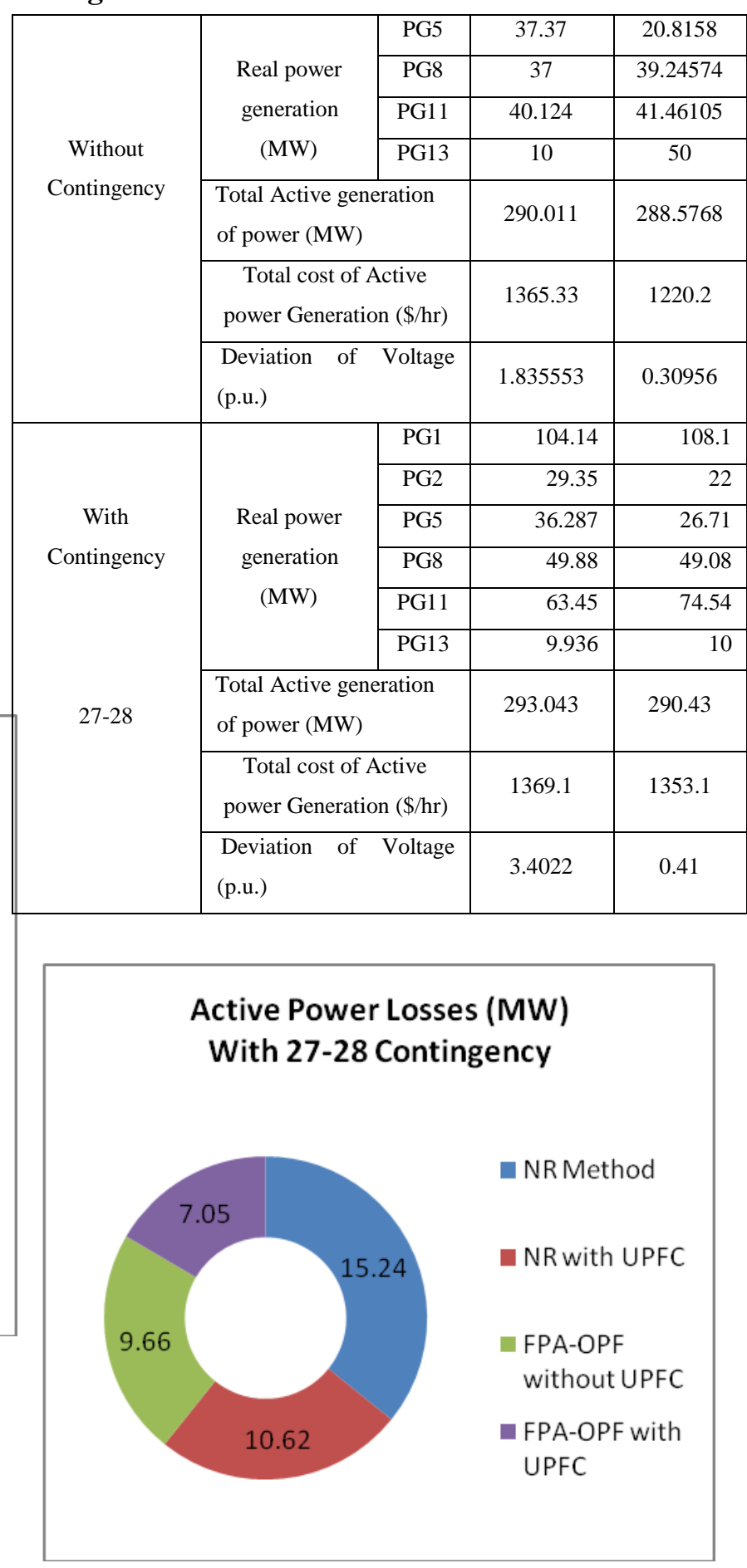

Fig.8 Assessment of Active Power Losses 


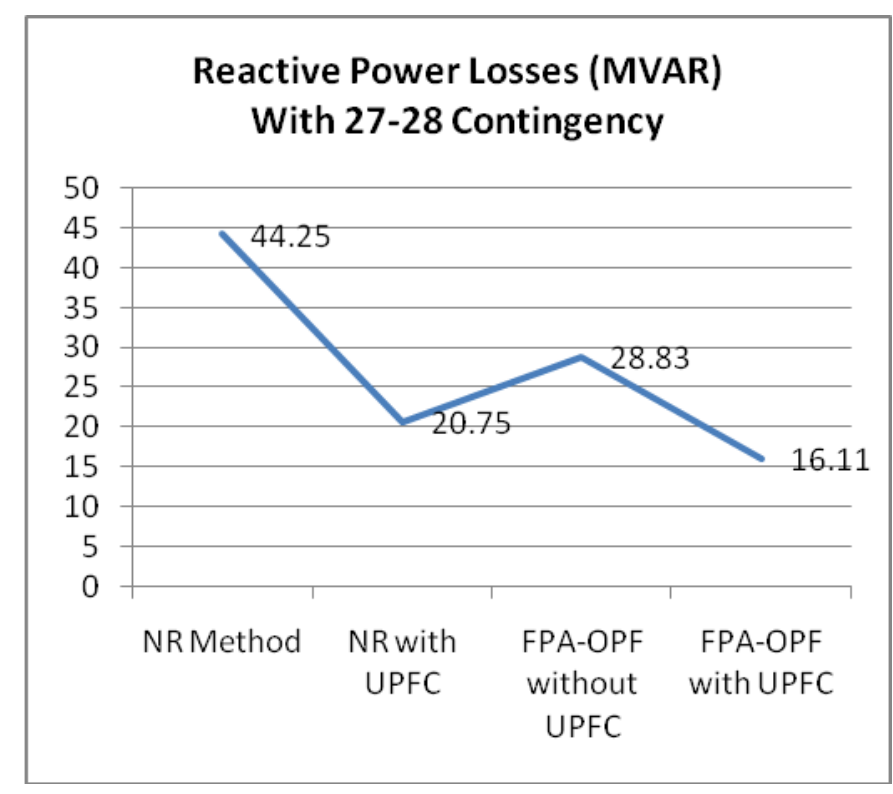

\section{Fig.9 Assessment of Reactive Power Losses}

Real power generation and cost of generation of the network have been evaluated for ordinary and faulty situation for OPF in absence and presence of UPFC in Table 2.OPF in the presence of UPFC reduces these parameters to a good extent. Contrast of Active and reactive power losses in various methods are presented in figures $8 \& 9$. The OPF with UPFC is found to be the better result in ordinary and faulty situation. The voltage summary of the 30 bus structure for OPF in absence and presence of UPFC has been assessed in Fig.10. The convergence characteristics presented in Fig. 11.

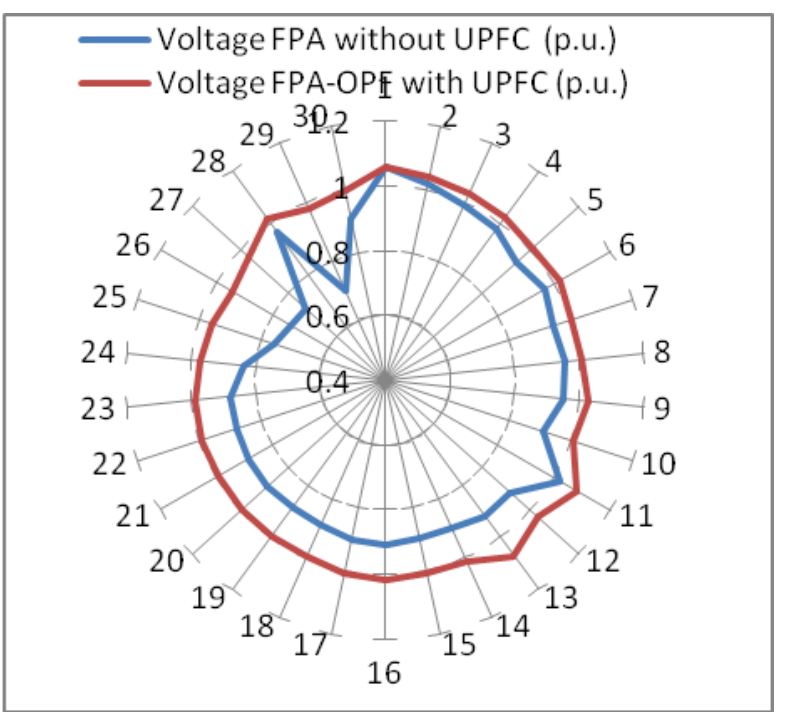

Fig.10 Assessment of bus voltages using FPA- OPF without and with UPFC

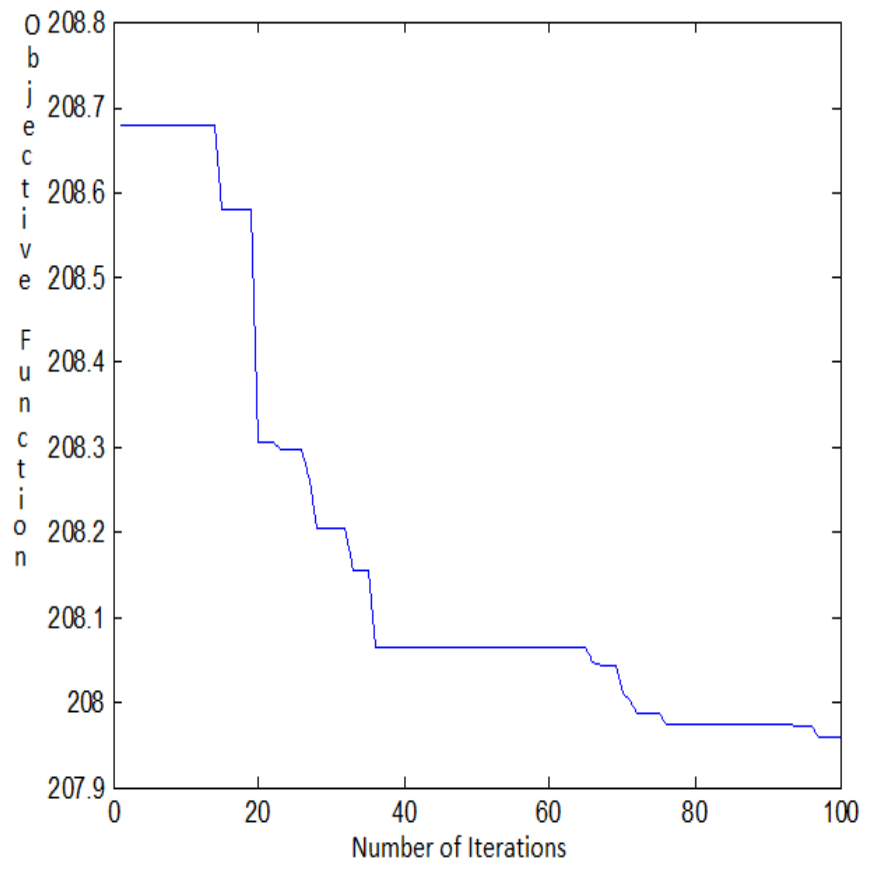

Fig.11Multi Objective function value Vs iterations

\section{FPA-OPF with UPFC}

\section{Conclusion}

- $\quad$ Optimal power flow using UPFC is observed in reduction of the contingency issues.

- $\quad$ The UPFC has been optimally placed in the system depending on L-index and LUF.

Flower pollination algorithm has been used for the optimization of the UPFC and generator parameters.

- $\quad$ The projected technique applied for an IEEE 30 bus system for $n-1$ contingency situation.

OPF using UPFC is observed to be an effective solution for enhancement of the system operation as seen in the values of the power system elements like decrease in Active power loss, deviation of voltage and fuel cost.

\section{REFERENCES}

1. Zhang, Qinghui Tang, Daxiang Deng, Yalin Chen, "A modified MOEA/D approach to the solution of multi-objective optimal power flow problem", Appl.Soft Comp.J. 2016, in press.

2. Bouchekara, A.E. Chaib, M.A. Abido, R.A. El-Sehiemy, 2016,"Optimal power flow using an Improved Colliding Bodies Optimization algorithm", Appl.Soft Comp.J.42, 119-131.

3. Rudra Pratap Singh, V. Mukherjee, S.P. Ghoshal,2016, "Particle swarm optimization with an aging leader and challengers algorithm for the solution of optimal power flow problem", Appl.Soft Comp.J. 40, 161-177.

4. Narges , Mehrdad Tarafdar Hagh , Saeed Teimourzadeh, 2016"Adaptive group search optimization algorithm for multi-objective optimal power flow problem", Appl.Soft Comp.J. 38, 1012-1024.

5. Mahdad, K. Srairi,2016, "Security constrained optimal power flow solution using new adaptive partitioning flower pollination algorithm", Appl.Soft Comp.J. 46, 501-522.

6. Biplab, Vikash Kumar Gupta, Sanjay Kumar,2014, "UPFC with series and shunt FACTS controllers for the economic operation of a power system", Ain Shams Engineering Journal. 5(3) , 775-787. 
Strategic Position and Tuning of UPFC using Multiple Indices and Flower pollination Algorithm for Contingency Management

7. Shaheen, G.I. Rashed, S.J. Cheng,2010 "Application and comparison of computational intelligence techniques for optimal location and parameter setting of UPFC", Engineering Applications of Artificial Intelligence. 23(2), 203-216.

\section{AUTHORS PROFILE}

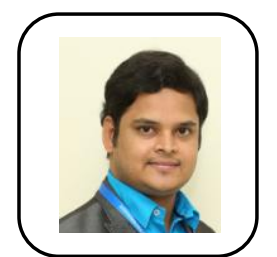

Dr.Sravana kumar Bali working as Assistant Professor in EEE Dept.,GITAM,Vizag,A.P,India.His area of interests are Power Systems, Contingency analysis, Algorithms and FACTS Devices.

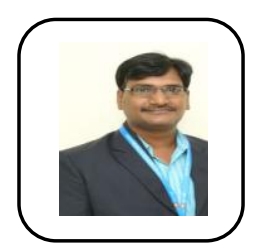

B.Durgaprasad working as Assistant Professor in EEE Department,GITAM,Vizag,A.P,India.His areas of interests are Power System Protection,Signal Processing and Distributed Generation.

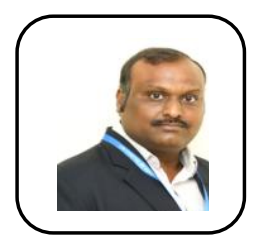

A.Jagdeesh working as Assistant Professor in EEE Department,GITAM,Vizag,A.P,India.His areas of interests are Power Systems and Gas insulated substations.

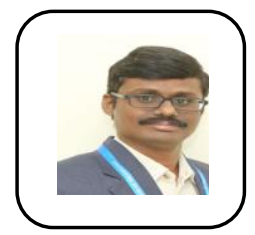

V.Rajakumarworking as Assistant Professor in EEE Department,GITAM,Vizag,A.P,India.His areas of interests are Power Systems, Distribution generation and non conventional energy sources. Email: coolvrajkumar@gmail.com 